\title{
Microsporum canis and other dermatophytes isolated from humans, dogs and cats in mexico city
}

\author{
Torres-Guerrero E ${ }^{1}$, González de Cossío AC ${ }^{1}$, Segundo ZC ${ }^{2}$, Cervantes ORA ${ }^{3}$, Ruiz- Esmenjaud $J^{1}$ and Arenas $\mathbf{R}^{1}$ \\ ${ }^{1}$ Sección de Micología. Hospital “Dr. Manuel Gea González”, Ciudad de México, México \\ ${ }^{2}$ Laboratorio de Micología Veterinaria, Unidad de Servicios de Diagnóstico y Constatación del Centro de Enseñanza, Investigación y Extensión en Producción \\ Animal en Altiplano. FMVZ.UNAM, México \\ ${ }^{3}$ Laboratorio de Micología del Depto. de Microbiología e Inmunología de la FMVZ. UNAM. México
}

\begin{abstract}
Introduction: Tineas or ringworm are infections caused by dermatophytes, a group of keratinophilic fungi.

According to origin and tropism can be classified as anthropophilics, zoophilics and geophilics.

Objectives: To obtain current data in zoophilic dermatophytes in humans and animals in Mexico City.

Material and methods: We performed an observational, descriptive and retrospective study, in two different Departments of Mycology. In a General Hospital we studied dermatophytic infections in 8,684 patients, (human cases), and in 480 animals (377 dogs and 103 cats) at the Faculty of Medical Veterinary, University of Mexico.

Results: 57 of the 8,684 human patients (0.65\%), had zoophilic dermatophytes: $M$. canis 43 (75.5\%), T. mentagrophytes var. mentagrophytes 13 (22.9\%) and $M$. nanum $1(1.6 \%) ; 40.8 \%$ were men and $59.2 \%$ females.

At the Veterinary Faculty, 377 samples from dogs and 103 from cats were studied, with 33 (8.73 \%) and 36 (34.95\%) positive cultures respectively. In dogs $M$. canis $72.70 \%$ Trichophytonterrestre $12.15 \%$, M. gypseum $9.10 \%$ and T. mentagrophytes $6.10 \%$, and in cats only M. canis was isolated.

Conclusions: In humans and in animals $M$. canis is still the main causal zoophilic agent. In children tineacapitis is the most frequent dermatopytosis. Tineacorporis is the second one, and usually related to close contact with infected pets.
\end{abstract}

\section{Introduction}

Tineas or ringworm are infections caused by keratinophilic fungi called dermatophytes that can also invade the skin and its appendages [1]. There are three anamorphicgenders: Trichophyton, Epidermophyton and Microsporum, none of which form part of the cutaneous flora. They can be classified according to its origin and tropism in anthropophilics, zoophilics and geophilics. These infections constitute 70 to $80 \%$ of all the mycoses and represent $5 \%$ of the dermatological consults $[2,3]$.

Infection is by direct contact with the causal agent and it can appear in any race, sex, socioeconomic level or occupation [3]. The animals act as reservoirs and can be symptomatic or just be carriers.

Among the zoophilic dermatophytes, Microsporumcanis and Trichophytonmentagrophytes, are of main medical relevance in Mexico.

The tineas are frequent in domestic and savage animals; they are found in bovine, pigs and equine as well as in poultry, the most affected ones, are the small species, such as dogs, cats and rodents. To acquire infection, a direct contact with the contaminated source is needed, soil or animal or it can also be transmitted from person to person or by fomites [3].

Our aim is to obtain the current frequency of the zoophilic dermatophytes in samples collected from patients and animals with a clinical diagnosis of tinea in a general hospital and in a veterinary clinic respectively.

\section{Material and methods}

We performed an observational, descriptive and retrospective study, in two departments of mycology, at "Dr. Manuel Gea Gonzalez" General Hospital, and at the Faculty of Medical Veterinary, Autonomous National University of Mexico (UNAM).

During a 10 year-period, a mycological study was performed, in 8684 patients with cutaneous lesions suggestive of tinea in the hospital and in the same period, 480 animals at the Faculty of Medical Veterinary, 377 dogs and 103 cats with suspected dermatophytes. All of them were included.

A direct exam with $20 \%$ potassium hydroxyde $(\mathrm{KOH})$ and a culture in Sabouraud dextrose agar with cycloheximide and chloramphenicol at $30^{\circ} \mathrm{C}$ were performed in samples from humans and animals. Identification was performed based in the morphologic criteria by the microscopic observation with lactophenol cotton blue.

Correspondence to: Dr. Roberto Arenas. Sección de Micología. División de Investigación. Hospital "Dr. Manuel Gea González". Calzada de Tlalpan 4800, Colonia "Belisario Domínguez, sección XVI”, Ciudad de México C.P. 14080. E-mail: rarenas98@hotmail.com

Received: March 01, 2016; Accepted: March 31, 2016; Published: April 04, 2016 


\section{Results}

From the 8,684 human patients, zoophilic dermatophytes were isolated only in 57(0.65\%) patients: $M$. canis $43(75.5 \%), T$. mentagrophytes (0.65\%) var. mentagrophytes 13 (22.9\%)and $M$. nanum 1 (1.6\%) (Graph 1), $40.8 \%$ were men and $59.2 \%$ females.

The most affected age groups were 0 to 10 (46.89\%); and the group 21 to 30 (12.5\%) (Graph 2). Clinical features are shown in Graph 3.

At the Veterinary Faculty, 480 samples from dogs and cats were studied: 377 from dogs and 103 from cats, with 33 (8.73\%) and 36 (34.95\%) positive cultures respectively. In dogs M. canis (72.70\%), TrJichophytonterrestre (12.15\%), M. gypseum (9.10\%) and T. mentagrophytes (6.10\%), were isolated, while in cats the only dermatophyte was M. canis (Graph 1).

\section{Discussion}

According with $4^{\text {th }}$ National Consensus of Superficial Mycoses in Mexico (2008), 70 to $80 \%$ of mycoses in outpatients were caused by dermatophytes [4]: $2 \%$ tineamannus, $4 \%$ tineacruris, $4-10 \%$ tineacapitis, $15 \%$ tineacorporis, $30 \%$ tineaungium and $45 \%$ tineapedis [4]. These data are considered on the basis of a general population, but only tineacapitis is almost always present just in children. [5]

In the current study, the majority of the cases in humans correspond to tineacapitis (46.89\%) followed by tineacorporis $(27.86 \%)$ because the highest percentage of patients was found from $0-10$ years of age (46.89\%).This data is congruent, as tineacapitis was the most frequent affected was the pediatric group, with an exceptional case in a 97 yearold female [5].

M. canis was the most frequent dermatophyte. It is present in $4.1 \%$ among general statistics and is the causal agent in 60 to $89 \%$ of tineacapitis in Mexican children [3,6]. The contact with domestic animals represents the main source of infection in up to $83 \%$. $[3,6]$ Similar results by Monteagudo [7], after his study conducted in Santiago de Compostela with 196 cases of tineacapitis, observed $M$. canis in 70-95\%, and T. mentagrophytes var. mentagrophytes in $14.8 \%$, and a low frequency of other non-zoophilic species. These data are different from USA reports, where the main causal agent of tineacapitis is T. tonsurans (90\%), the increase incidence of this agent is related to migrations of Afro-Americans and Latin American [3,8]. Also in Madrid, T. tonsurans' incidence has increased in the last years, and $M$ canis is now in the second place. In Puerto Rico about two thirds of tineacapitis are caused by T. tonsurans and the other third by M. canis

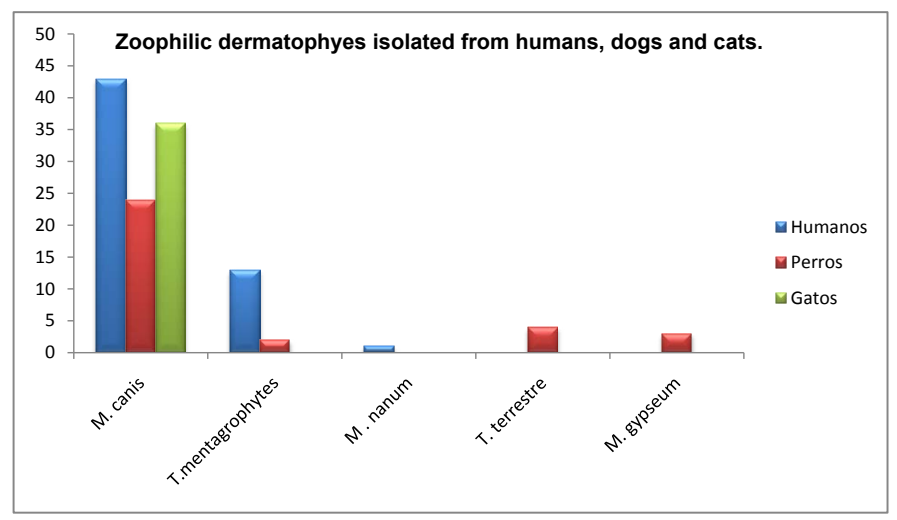

Graph 1. Zoophilic dermatophytes isolated from humans, dogs and cats.

\section{Frequency of dermatophytoses in each age group}

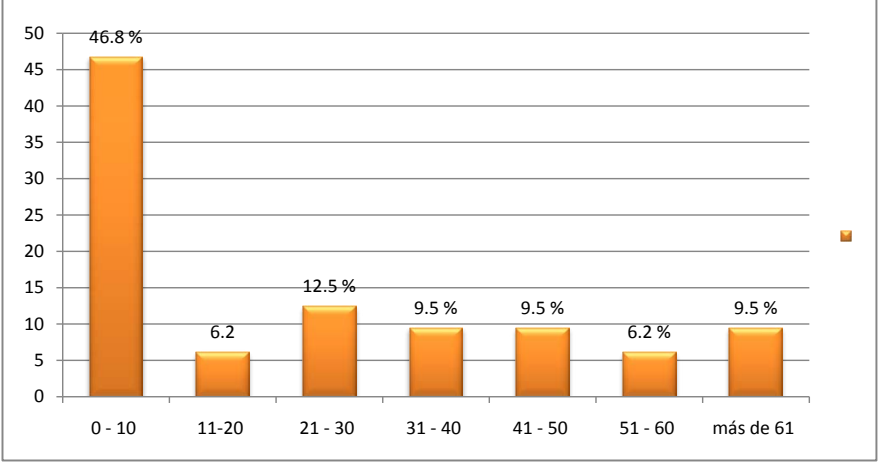

Graph 2. Frequency of dermatohytoses according to age group.

Clinical forms of tinea caused by zoophilic dermatophytes

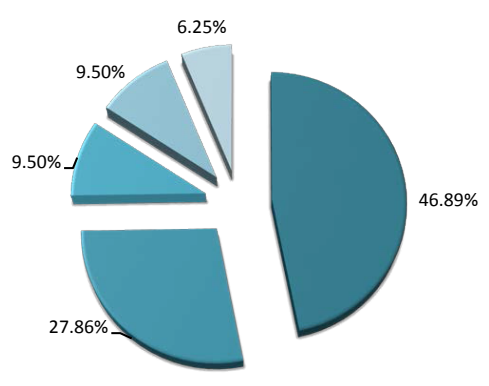

Tinea capitis

Tinea corporis

Q Onicomicosis

$\square$ Afección en cara

$\square$ Tinea pedis

Graph 3. Clinical human dermatophytic infections caused by zoophylic dermatophytes.

[9].

In Jordan after conducting a 6 years epidemiological study, Shagra [10] found T. violaceum as the main causal agent in tineacapitis, and in second place, M. canis. Mseddi and Makni in Tunez, separately reported 83 and $68 \%$ tineacapitis caused by T. violaceum, and M. canis in $29.2 \%$ [11,12]. Also Ouidaina, in Morocco, after finishing a study with 1299 patients from 1993 to 2007, identified 76.4\% of tineacapitis due to T. mentagrophytes, while $M$. canis $13.4 \%$ [13]. In the same country, Boumhil, studied 162 patients from 2002 to 2008, finding $63.58 \%$ of infections due to T. violaceum and $33.33 \%$ to M. canis [14]. Arenas et $a l$., reported in an epidemiological study conducted in the urban and rural zones of Dominican Republic, a resurging of M. audouinii and T. tonsurans respectively, probably due to the migratory movements from Haiti, while M. canis was found in $19.04 \%$ and $11.65 \%$ respectively [15].

Tineacorporis, ranked second in frequency of the clinical forms observed in our study (27.86\%). According to the National Consensus of Superficial Mycoses [4], T. rubrum was the main causal agent, followed by $M$. canis, however it must be considered that tineacorporis caused by $M$. canis is more typical of pediatric patients, as we are reporting in this paper. In a retrospective study in Mexico 357 cases oftineacorporis were reported in 21 years, and M. canis was found in $16.7 \%$ [16]. Meanwhile, Cafarchia et al. [17], in 2005, performed in Bari, Italy, a dermatophitic search in dogs and cats, which owner had or had not tinea and found M. canis in $53.6 \%$ of cats and $36.4 \%$ in dogs whose owners had tinea, and in only $14.6 \%$ of cats and non in the dogs which owners did not have tinea, concluding that one must be aware that the animals are a source of infection. 
Concerning tineafaciei (20\% of tineacorporis) and onychomycosis, in this study each one was present in 9.5\%. In Italy, Monod performed a study of facial tinea caused by $M$. canis, reporting $91.3 \%$ of the children infected by their pets. [18] According to Romano et al., the medium age in tineafaciei is close to 27 years of age, while in Aste et al., paper, it is more common between 36 and 45 years of age. [19] Our facial cases were found in the age group of 20 to 50 years.

We found a lower frequency of $M$. canis in other dermatophytic infections, $9.5 \%$ in onychomycoses and $6.25 \%$ in tineapedis. Kazemi, in Iran, studied 590 patients from 1996 till 2004, found zoophiticdermatophytes such as T. mentagrophytes and M. canis, with a frequency of $65.5 \%$ of cases with onychomycosis; Sei in Japan, identified $M$. canis in just 5 cases in 36,052 ambulatory patients. In feet and nails, $M$. canis is uncommon but Trichophyton sppare more contagious and responsible of outbreaks in endemic countries, and zoophilic fungi are just related to small familiar epidemics [20-22].

From the veterinary point of view, Microsporumcanis is the most common dermatophyte in pets [18]. Worldwide $90-100 \%$ of dermatophytoses in cats are caused by $M$. canis [23] and usually its isolation in asymptomatic animals indicates subclinical infection or carrier [24].

In the laboratory of the faculty of veterinary medicine at the UNAM, $100 \%$ of $M$. canis was reported in the hair of cats and $72.70 \%$ in dogs, similar to Lorio in Italy, who showed that the stray cats are an important source of dermatomycosis, because he isolated fungi in $100 \%$ of the hair samples [25]. Boumhil in Moroco reported that $56.7 \%$ of the cases with tineacapitis have been originated from direct contact with animals [14]. Cafarchia in Italy and Seker in Turkey [26,27], described that in animals one of the main risks to acquire dematophytoses was the age. Moriello, found that cats with the immunodeficiency Felline virus, the dermatophytosis are three times more prevalent [28].

In this study M. gypseum was isolated in a $9.10 \%$ of dogs' samples, which differs from the reported percentage by Álvarez et al., in Colombia, who isolated M. gypseum in $55.9 \%$ in stray dogs and owned dogs in a study in 2001 [29]; Madrid et al., in Brazil, from 7 dogs, 20 day-old, $M$ gypseum was isolated [30].

The isolation of M. gypseum in animals, occurs less frequently and its presence is in general attributed to its geophilic character, besides external and internal factors that can alter the normal microbiota of normal animal's skin and this way the infection process is favor, as has been proven in previous studies by Levy et al.. Those who determined the presence of dermatophytes in the hair of cats in cautivity, found M. gypseum in $1.6 \%$ of animals and they attributed this finding to the humid conditions, $\mathrm{pH}$ and fecal contamination of the place where they are housed [31].

As mentioned before T. mentagrophytes, is isolated in different inflammatory entities in the head and nails, but in animals this dermatophyte was isolated just in dogs (6.10\%). This dermatophyte has been reported in rodents and less frequently in dogs and other mammals. Murmu et al. in a previous study isolated in $16.7 \%$ from dogs' hair, skin and nails with suggestive lesions of dematophytoses [32]. In India Gangil et al., isolated T. mentagrophytes in 18.3\% from dogs with skin lesions [33], while in Baghdad, Jasim isolated 30.95\% in dogs, from samples taken from various body sites [34].These data contrast with our findings as we found a lower frequency that the previously cited authors, but this finding becomes relevant as it can be a source of infection or re-infection in human and animals, so better hygienic conditions are recommended to dogs' owners as well as in places where animals are too close to each other (aesthetic canines and veterinary clinics).

T. terrestre was isolated just in dogs (12.15\%), similar to $M$. gypseum, though its presence can be attributed to its geophilic character, but different form the last one, it is considered as a causal agent of dematophytoses in animals. T. terrestre doesnot count with conclusive evidence to confirm its role in dematophytoses in dogs, attributing their presence to the rather natural behavior of the animal, as when they smell, their snout is in direct contact with the soil, the source of dermatophyte infection [35].

\section{Conclusions}

M. canis is the most frequent zoophilic dermatophyte isolated from humans and animals. It is still the main causal dermatophyte for tineacapitis in children and tineacorporis in young adults. This group is the most frequently affected, because afterward in puberty long-chain fat acids are in the scalp and have a protective role.

Also, children are more often in direct contact with pets. Infections may be related with poor hygiene especially when animals are too close to each other (esthetics and veterinary clinics) and can become a focus of infection. Zoophilic or geophilicdermatophytes could also be the cause of family epidemics.

\section{References}

1. López-Martínez R, Méndez-Tovar LJ, Hernández-Hernández F, Castañón - Olivares R (2006) Micología Médica. Procedimientos para el diagnóstico de laboratorio $\left(2^{\text {nd }}\right.$ edtn). En: Trillas, México, 31-46.

2. Arenas R (2002) [Dermatophytoses in Mexico]. Rev Iberoam Micol 19: 63-67. [Crossref]

3. Arenas R (2015) Micología Médica Ilustrada (5 $5^{\text {th }}$ Edtn). Mc Graw Hill Companies, México. Pp: 67-98.

4. Micosis Superficiales (2008) Cuarta revisión del Consenso Nacional de Prevención, Diagnóstico y Tratamiento. México, Universidad Nacional Autónoma de México. Pp. $20-24$.

5. Torres-Guerrero E, Leal- Osuna S, Clavellina M, Solís P, Arenas R (2014) Tinea capitis en pacientes geriátricas. Informe de dos casos por Trichophyton tonsurans y Microsporum canis. Revista Colombiana de Gerontología y Geriatría 28: 1942-1954

6. Segundo C, Martínez A, Arenas R, Fernández R, Cervantes RA (2004) [Superficial infections caused by Microsporum canis in humans and animals]. Rev Iberoam Micol 21: 39-41. [Crossref]

7. Moriello K (2012) Dermatophytosis ( $4^{\text {th }}$ edtn). Infectious diseases of the dog and cat Elsevier, St. Louis, USA. Pp: 588-602.

8. Elewski B, Hughey L, Sobera OJ, Hay R (2012) Fungal Diseases. Dermatology (3 $3^{\text {rd }}$ Edtn). Elsevier Saunders, New York. Pp: 1251-1285.

9. Ginter-Hanselmayer G, Weger W, Ilkit M, Smolle J (2007) Epidemiology of tinea capitis in Europe: current state and changing patterns. Mycoses 50 Suppl 2: 6-13. [Crossref]

10. Abu Shaqra QM, Al Momani W (2011) Cases of tinea capitis as encountered in a private practice laboratory from Jordan. J Mycol Med 21: 24-27. [Crossref]

11. Makni F, Néji S, Sellami A, Cheikrouhou F, Sellami H, et al. (2008) Les teignes du cuir chevelu dans la région de Sfax (Tunisie). J Med Mycol 18: 162-165.

12. Mseddi M, Merrekchi S, Sellami H, Mnif E, Boudaya S, et al. (2005) Les teignes de l'adulte: étude restróspective dans le sud Tunisien. J Med Mycol 15: 93-96.

13. Oudaina W, Biougnach H, Riane S, El Yaagoubil I, Tangi R, et al. (2011) [Epidemiology of tinea capitis in outpatients at the Children's Hospital in Rabat (Morocco)]. J Mycol Med 21: 1-5. [Crossref]

14. Boumhil L, Hjira N, Naoui H, Zerrour A, Bhirich N, et al. (2010) Les teignes du cuir chevelu á 1' hópital militaire d' instruction Mohammed V (Maroc). J Med Mycol 20: 97-100. 
15. Arenas R, Torres E, Amaya M, Rivera ER, Espinal A, et al. (2010) Tinea capitis. Emergencia de Microsporum audouinii y Trichophyton tonsurans en la República Dominicana. Actas dermosifilogr 101: 330-335.

16. Guevara-Cervantes JF, Marioni-Manríqez S, Tello-Ibáñez OO, Vega DC, Vázquez del Mercado E, et al. (2015) Tinea corporis. Estudio micológico y epidemiológico de 357 casos. DCMQ 13: 282-288

17. Cafarchia C, Romito D, Capelli G, Guillot J, Otranto D (2006) Isolation of Microsporum canis from the hair coat of pet dogs and cats belonging to owners diagnosed with $M$. canis tinea corporis. Vet Dermatol 17: 327-331. [Crossref]

18. Monod M (2008) Secreted proteases from dermatophytes. Mycopathologia 166: 285294. [Crossref]

19. Torres-Guerrero E, Ramos-Betancourt L, Martínez-Herrera E, Arroyo-Camarena S, Porras C, et al. (2015) Dermatophytic blefaritis due to Microsporum gypseum. An adult variety of tinea faciei with dermatophytoma. Our Dermatol Online 6: 36-38.

20. Kazemi A (2007) Tinea unguium in the north-west of Iran (1996-2004). Rev Iberoam Micol 24: 113-117. [Crossref]

21. Sei Y (2015) [2011 Epidemiological Survey of Dermatomycoses in Japan]. Med Mycol J 56: J129-135. [Crossref]

22. Abd Elmegeed AS, Ouf SA, Moussa TA, Eltahlawi SM (2015) Dermatophytes and other associated fungi in patients attending to some hospitals in Egypt. Braz J Microbiol 46: 799-805. [Crossref]

23. Monteagudo B, Pereiro M Jr, Peteiro C, Toribio J (2003) Tinea capitis en el área sanitaria de Santiago de Compostela Actas Dermosifilogr 94: 598-602.

24. Frymus T, Gruffydd-Jones T, Pennisi MG, Addie D, Belák S, et al. (2013) Dermatophytosis in cats: ABCD guidelines on prevention and management. $J$ Feline Med Surg 15: 598-604. [Crossref]
25. Iorio R, Cafarchia C, Capelli G, Fasciocco D, Otranto D, et al. (2007) Dermatophytoses in cats and humans in central Italy: epidemiological aspects. Mycoses 50: 491-495. [Crossref]

26. Cafarchia C, Romito D, Sasanelli M, Lia R, Capelli G, et al. (2004) The epidemiology of canine and feline dermatophytoses in southern Italy. Mycoses 47: 508-513. [Crossref]

27. Seker E, Dogan N (2011) Isolation of dermatophytes from dogs and cats with suspected dermatophytosis in Western Turkey. Prev Vet Med 98: 46-51. [Crossref]

28. Moriello KA (2004) Treatment of dermatophytosis in dogs and cats: review of published studies. Vet Dermatol 15: 99-107. [Crossref]

29. Álvarez MI, Caicedo LD (2001) Dermatofitos en perros de Cali, Colombia. Biomédica 21: 128-133.

30. Madrid IM, Dos Reis Gomes A, Souza Mattei A, Santin R, Brum-Cleff M, et al. (2012) Dermatofitose neonatal canina por Microsporum gypseum. Vet Zootec 19: 073-078.

31. Levy Bentubo HD, Luzes Fedullo JD, Ramiro Corrêa SH, Hidalgo R, Teixeira F, et al. (2006) Isolation of Microsporum gypseum from the haircoat of health wild felids kept in captivity in Brazil. Braz J Microbiol 37:148-152.

32. Murmu S, Debnath C, Pramanik AK, Mitra T, Jana S, et al. (2015) Detection and characterization of zoonotic dermatophytes from dogs and cats in and around Kolkata. Vet World 8: 1078-1082.

33. Gangil R, Dutta P, Tripathi R, Singathia R, Lakhotia RL (2012) Incidence of dermatophytosis in canine cases presented at Apollo Veterinary College, Rajashtan, India. Vet World 5: 682-684.

34. Mohammed JS (2013) Dermaophytes for isolated from dogs suspected of dermatophytosis in Baghdad City. Diyala Journal for Pure Sciences 9: 61-66.

35. Viguie-Vallanet C, Paugam A (2009) Dermatofitos transmitidos por animales. Acta bioquim clin Latinoam 43: 263-270.

Copyright: (C2016 Torres-Guerrero E. This is an open-access article distributed under the terms of the Creative Commons Attribution License, which permits unrestricted use, distribution, and reproduction in any medium, provided the original author and source are credited. 